\title{
THE 1995 ICCA BEST-ANNOTATION AWARD
}

\author{
The Board of ICCA
}

The best-annotation award is for the program which provides the best annotations to an input chess game. Contestants must submit a program capable of running under either MS-DOS, Windows or UNIX. Input to the program will be provided by the ICCA in the form of a chess game presented as an ASCII text file, using the notation 'from square to square' (e.g., e2e4). Contestants must submit their programs by December 31, 1995 and the ICCA will provide input identical for all entries. Nominations by program authors or others are eligible for the Award if submitted as certified copies in machine-executable form to ICCA President Tony Marsland, University of Alberta, Dept. of Computing Science, Edmonton, Alberta T6G 2H1, Canada. The copies should be accompanied by at least the amount of documentation required to operate the program in one of the operating environments listed. The judges will be chess experts and are charged to adjudicate the Award on the basis of the state of the art in programmed game annotation. It is hoped to secure sponsorship to provide a prize of some substance, in addition to suitable publicity in the Journal for the program as a product.

\section{THE 1994 ICCA JOURNAL AWARD}

\section{The Board of ICCA}

In 1992, a novel award was instituted by the ICCA, the ICCA Journal Award. The ICCA Journal Award is to be adjudicated to the best author on computer chess for an article in the ICCA Journal. The first ICCA Journal Award (1993) covered the articles published in the issues Vol. 15, No. 2 up to and including Vol. 16, No. 1. Peter Jansen was the first winner of the ICCA Journal Award. Peter Jansen has been granted the award for his article KQKR: Awareness of a Fallible Opponent as published in Vol. 15., No. 3, pp. 111-131.

The second ICCA Journal Award covers the articles published in the issues Vol. 16, No. 2 up to and including Vol. 17, No. 1. The winner will receive a hand-lettered certificate to this effect and will have a choice of any three volumes of the Journal's back issues. The name of the winning author will also, of course, be published in the ICCA Journal with a short curriculum vitae if so desired and an abbreviated version of the jury's report, giving reasons for their choice. The judges will be computer-chess experts with proved expertise in technical writing. The winner of the second ICCA Journal Award will be announced in Vol. 18, No. 2.

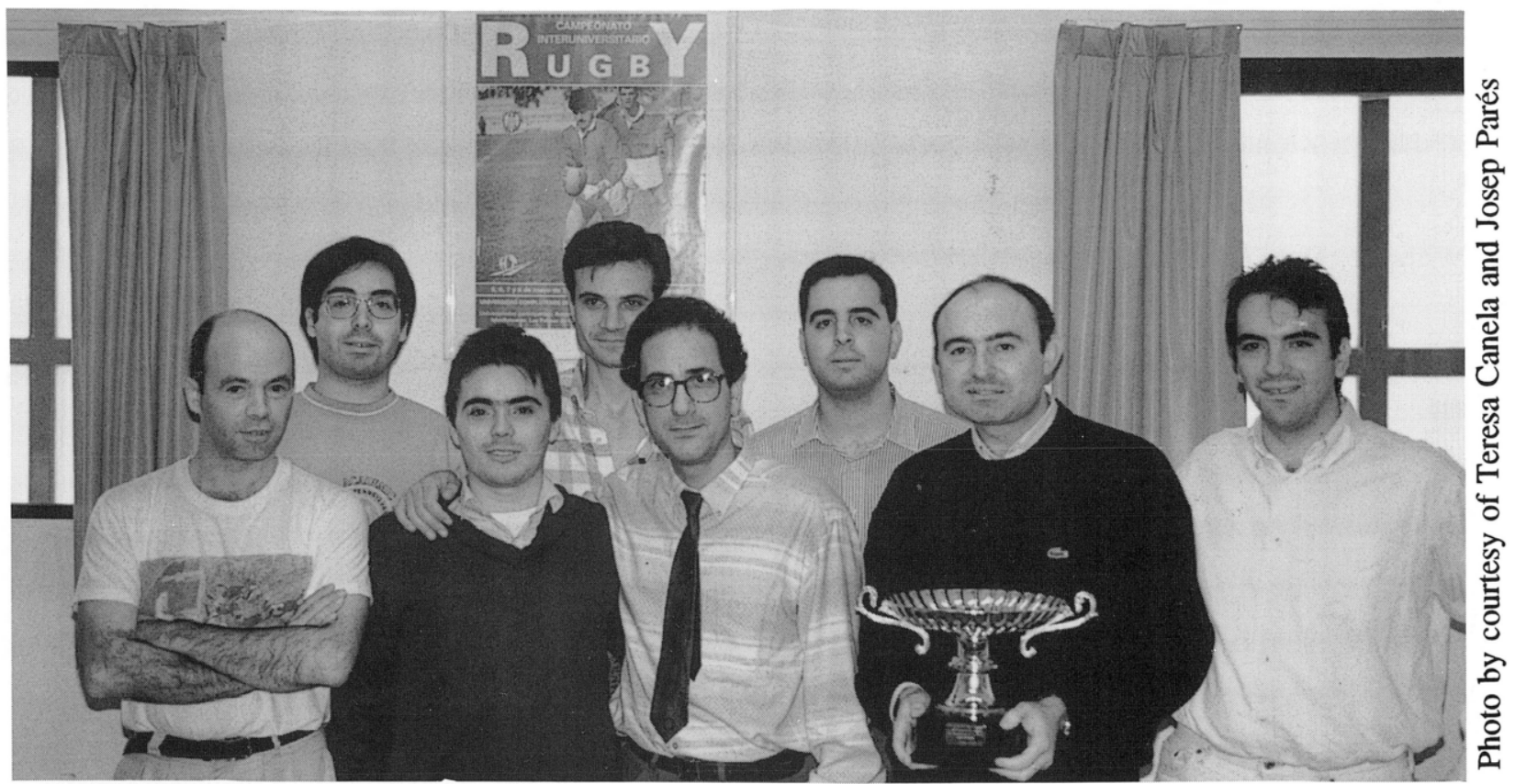

HOPEFUL MATADORES ALL

The Spanish programmers here assembled can never forget that matar also means giving checkmate. 